\title{
Karakteristik Fisiologis Lumut pada Beberapa Ketinggian di Kawasan Gunung Tangkuban Perahu
}

\section{Physiological Characteristics of Moss at some Altitudes of Tangkuban Perahu Mountain}

\author{
Hirmas Fuady Putra ${ }^{1^{*}}$, Dhenok Sekar Ambarwati ${ }^{2}$, Nurrizki Mubyarsih ${ }^{2}$, Tersi Alesti $^{3}$ \\ ${ }^{1}$ Department of Biology, Faculty of Mathematics and Natural Sciences, Bogor Agricultural University \\ ${ }^{2}$ School of Life Sciences and Technology, Bandung Institute of Technology \\ ${ }^{3}$ Department of Biology, Bangka Belitung University
}

Diterima 29 Oktober 2015/Disetujui 03 September 2015

\begin{abstract}
Environmental factors greatly influence the physiological state of moss. Some of the environmental factors that influence the physiological of moss are air temperature, humidity, and light intensity. These three environmental factors will vary at each altitude. This study aims to determine the physiological characteristics of mosses on some altitudes in the area of Mount Tangkuban Perahu (Ratu Crater - Domas Crater track). The method that are used is to measure air temperature, humidity, and light intensity at some altitudes. Subsequently, samples were taken at each altitude, to measured chlorophyll and proline content. Mosses that are used as samples; Campylopus sp., Plagiochila sp., Dicranella sp. The results indicate that the chlorophyll content significantly different at some altitude, with an increasing trend as the decrease altitude. The highest chlorophyll content in Campylopus sp. at altitude of 1,621 meters above sea level, while the lowest chlorophyll content in Plagiochila sp. at altitude of 1,721 meters above sea level. The content of proline did not differ significantly at some altitude, and tend to be more affected by air conditions that correlate with distance of moss habitat with the active crater of Domas, which allegedly can cause physiological stress in the moss.
\end{abstract}

Key words: moss, altitudes, chlorophyll, proline, Tangkuban Perahu.

\section{PENDAHULUAN}

Lumut merupakan tumbuhan tingkat rendah yang tidak memiliki jaringan pembuluh. Lumut pada umumnya berukuran kecil dan tumbuh dengan menempel pada berbagai macam substrat, seperti tanah, batu, batang tumbuhan dan sebagainya. Lumut banyak ditemukan di daerah-daerah lembab, bercahaya dan pada ekosistem terrestrial (Siregar, 2010).Di dalam kehidupannya, factor lingkungan sangat berpengaruh, seperti iklim mikro yang lebih berpengaruh pada pertumbuhan dan perkembangan lumut dari pada factor makro (HasandanAriyanti, 2004).

Gunung Tangkuban perahu terletak antara $107^{\circ} 30^{\prime}$ sampai $107^{\circ} 40^{\prime} \mathrm{BT}$ dan $6^{\circ} 40^{\prime}$ sampai $6^{\circ} 50 \mathrm{LS}$ yang dibagi menadi 2 daerah yakni Taman Wisata Alam dengan luas $370 \mathrm{Ha}$ dan Cagar Alam dengan luas 1.290 Ha Secara keseluruhan, kondisi lapangan menurun dengan tingkat kelerengan 30\% sampai 50\% (Iskandar et al. 2008).

Pada prinsipnya, setiap tumbuhan memiliki saran

${ }^{*}$ Penulis korespondensi : +62-251-8622833

E-mail: hirmas_fp@yahoo.co.id tertentu terhadap factor lingkungannya. Prinsip tersebut dinyatakan sebagai Hukum Toleransi Shelford yang berbunyi "Setiap organisme mempunyai suatu minimum dan maksimum ekologis, yang merupakan batas bawah dan batas atas dari kisaran toleransi organisme itu terhadap kondisi factor lingkungannya" (Dharmawan 2005).Kondisi diatas ataupun dibawah batas kisaran toleransi itu, mahluk hidup akan mengalami stress (cekaman) fisiologis. Pada kondisi cekaman fisiologis ini, populasi akan menurun. Apabila kondisi cekaman ini terus berlangsung dalam waktu yang lama dan telah mencapai batas toleransi kelulushidupan, maka organisme tersebut akan mati.

Lakitan (1995) menyebutkan bahwa factor lingkungan yang mempengaruhi pertumbuhan dan perkembangan daun antara lain intensitas cahaya, suhu, udara, ketersediaan air, dan unsur hara. Berat dan volume daun maksimum lebih tinggi pada intensitas cahaya yang tinggi, tetapi luas daun maksimum telah tercapai pada intensitas cahaya yang relative rendah.

Indrawan etal.(2007)menyatakan bahwa ketinggian bersama faktor lain seperti iklim dan kesuburan tanah akan menentukan kekayaan spesies pada tingkat habitat. Sementara itu, faktor-faktor fisiografis merupakan 
keadaan yang secara tidak langsung mempengaruhi vegetasi hutan melalui efeknya terhadap faktor-faktor yang berpengaruh langsung. Faktor-faktor tersebut antara lain ketinggian tempat (altitude) kemiringan lereng (slope) dan arah mengahadap lereng (aspek). Perbedaan ketinggian tempatakan berpengaruh terhadap kelembaban, suhu, intensitas cahaya dan curah hujan. Semua proses fisiologi akan dipengaruhi suhu dan beberapa proses akan tergantung dari cahaya (Yuliani, 2010). Faktor lingkungan tersebut yang mempengaruhi proses fisiologis tumbuhan sehingga diduga bahwa karakteristik fisiologis lumut akan bervariasi terhadap ketinggian. Raffensperger \& Wood (2005) menduga bahwa keberadaan lumut akan bertambah seiring dengan ketinggian dan berkurang pada ketinggian tempat paling tinggi dimana area permukaan yang luas membuat rentan terhadap angin.

Pengertian ekofisiologis secara umum adalah hubungan antara fungsi fisik makhluk hidup dengan lingkungannya, atau dalam hal ini bagaimana tumbuhan berespon terhadap lingkungannya (Pitriana, 2003). Menurut Pitriana (2003), kondisi iklim mikro dan substrat tumbuh yang berbeda, maka kondisi ekofisiologis lumut kerak pun berbeda. Mengingat adanya pengaruh factor lingkungan terhadap pertumbuhan lumut, seperti yang telah dipaparkan sebelumnya, maka penelitian ini dilakukan dengan tujuan mengetahui karakteristik fisiologis lumut pada beberapa ketinggian di Kawasan Gunung Tangkuban Perahu (Kawah Ratu - Kawah Domas).

\section{BAHAN DAN METODE}

Pengambilan sampel untuk mengetahui respon fisiologis lumut di jalur Kawah Ratu-Kawah Domas, Gunung Tangkuban Perahu dilakukan pada bulanAprilMei2012. Sampel lumut diam bilpada3 titik ketinggian berbeda, yaitu titik A 1821 mdpl, titik B 1721 mdpl dan titik C 1621 mdpl. Pada tiap titik pengambilan sampel dilakukan pengukuran factor lingkungan berupa: intensitas cahaya, suhu udara, dan kelembaban udara.

Lumutyang dijadikan sampel terdiri atas tiga spesies lumut yaitu Campylopus sp., Plagiochila sp. dan Dicranella sp. Penentuan spesies lumutyang digunakan adalah spesies lumut yang sama yang berada pada 3 titik yang berbeda ketinggian di jalur kawah ratu - kawah domas. Penggunaan spesies yang sama pada penelitian ini bertujuan untuk membandingkan respon fisiologis lumut(khususnya spesies yang dipilih)yang hiduppada habitat yang memiliki ketinggian yang berbeda.

Parameter responfisiologis yang kami ukur adalah kandungan klorofil dan kandungan prolin. Sampel lumut diambil beserta substrat untuk identifikasi spesies. Sampel lumut untuk uji klorofil dan prolin diambil dan dipotong dari bagian folia langsung di lokasi, kemudian dimasukkan dalam botol film yang telah disiapkan. Jumlah total sampelyang diambiladalah 9 sampel. Klorofil diestimasi dengan menggunakan metode spektrofotometri. Uji prolin dilakukan berdasarkan Bates, Waldren dan Teare (1973). Hasil yang diperoleh adalah $\mathrm{mg} / 5 \mathrm{ml}$ toluen. Selanjutnya, data kandunganklorofildan prolin pada lumut dianalisis secara statistik (menggunakan piranti lunak SPSS) pada selang kepercayaan $95 \%$. Kemudian dilakukan uji homogenisitas berdasarkan uji Duncan.

\section{HASIL}

Parameter Kondisi Lingkungan dariHabitat LumutpadaTiap Ketinggian. Berdasarkanpengukuran yang dilakukan, diperoleh perbedaan pada beberapa parameter lingkungan pada tiap ketinggian dari ketinggian 1.821 mdpl-1.621 mdpl(Tabel 1).

Tabel 1. Parameter Kondisi Lingkungan pada Tiap Ketinggian

\begin{tabular}{llll}
\hline \multicolumn{1}{c}{ Parameter } & \multicolumn{1}{c}{$\begin{array}{c}\text { Ketinggian } \\
\text { I }\end{array}$} & $\begin{array}{c}\text { Ketinggian } \\
\text { II }\end{array}$ & $\begin{array}{c}\text { Ketinggian } \\
\text { III }\end{array}$ \\
& $(1.821 \mathrm{mdpl})$ & $(1.721 \mathrm{mdpl})$ & $(1.621 \mathrm{mdpl})$ \\
\hline $\begin{array}{l}\text { Suhu udara } \\
\text { Kelembapan }\end{array}$ & $23^{\circ} \mathrm{C}$ & $24^{\circ} \mathrm{C}$ & $25^{\circ} \mathrm{C}$ \\
$\begin{array}{l}\text { udara } \\
\begin{array}{l}\text { Intensitas } \\
\text { cahaya matahari }\end{array}\end{array}$ & $74 \%$ & $52 \%$ & $54 \%$ \\
(lux $)$ & $8700-8800$ & $10900-11100$ & $12400-12500$ \\
\hline
\end{tabular}

Kandungan KlorofilLumutpada Tiap Ketinggian. Pada Campylopus sp. (spesies A), kandungan klorofil cenderung meningkat seiring menurunnya ketinggian habitat lumut tersebut(Gambar 1). Pada grafik klorofil total, terlihat perbedaan yang nyata antara ketinggian I dengan ketinggian II dan III. Kandungan klorofil tertinggi pada spesies Campylopus sp. ini adalah pada ketinggian III.

Sedangkan pada Plagiochila sp. (spesies B), kandungan klorofil total berbeda nyata pada tiap ketinggian. Selain itu, pada spesies ini, kandungan klorofil a, b, dan total pada ketinggian II merupakan yang terkecil, yaitu $1,06 \mathrm{mgl}^{-1}$ (klorofil total). Kandungan klorofil tertinggi masih padaketinggian III, yaitu sebesar $2,52 \mathrm{mgl}^{-1}$ (Gambar 2).

Pada Dicranella sp., data klorofil yang diperoleh hanya pada ketinggian I dan II, dikarenakan pada waktu pengambilan sampel spesies tersebutbelum ditemukan pada ketinggian III. Berdasarkandatakandunganklorofil $a, b$, dan total tampak tidak ada perbedaan nyata antar ketinggian. Kandungan klorofil total pada ketinggian I: 2,01 $\mathrm{mgl}^{-1}$, sedangkan pada ketinggian II: $1,95 \mathrm{mgl}^{-1}$ (Gambar3). 


\section{Kandungan Prolin Lumut pada Tiap Ketinggian.}

Untuk data kandungan prolin, seperti tampak pada grafik tidak terlihat perbedaan nyata antar tiap ketinggian untuk semua spesies lumut (Campylopus sp. ,Plagiochila sp., dan Dicranella sp.). Namun, secara umum kandungan prolin pada lumut di ketinggian II paling besar, yaitu $0,096 \mu \mathrm{molg}^{-1}$ pada Campylopus dan $0,070 \mu \mathrm{molg}^{-1}$ pada Plagiochila $\mathrm{sp}$. (Gambar 4).
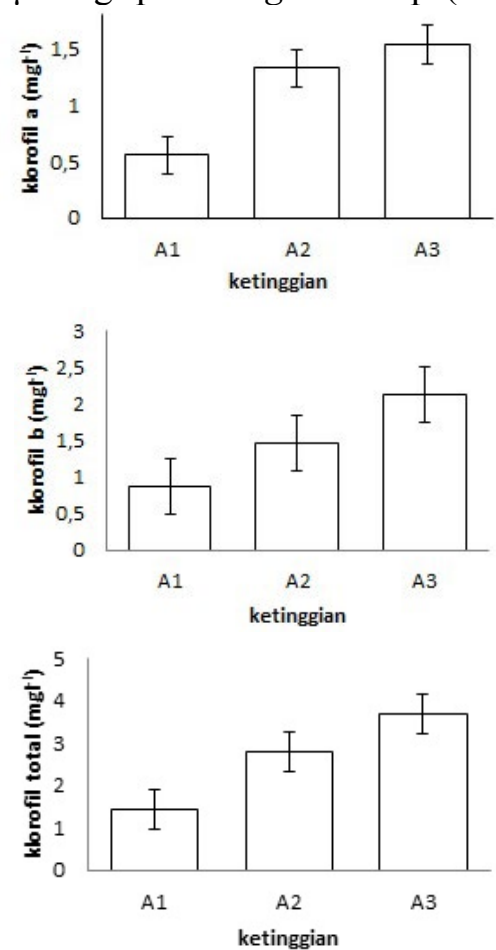

Gambar 1. Kandungan klorofil lumut spesies A pada tiap ketinggian
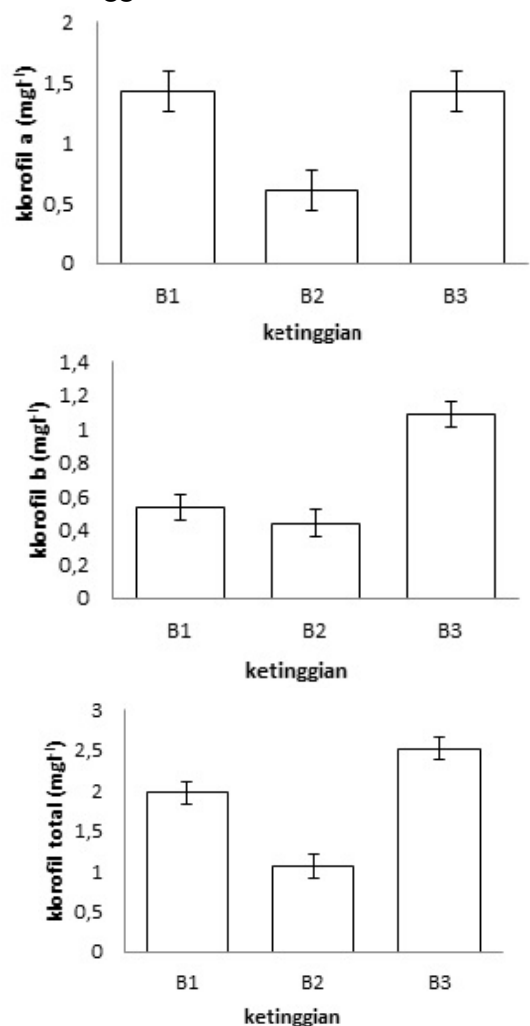

Gambar 2. Kandungan klorofil lumut spesies B pada tiap ketinggian
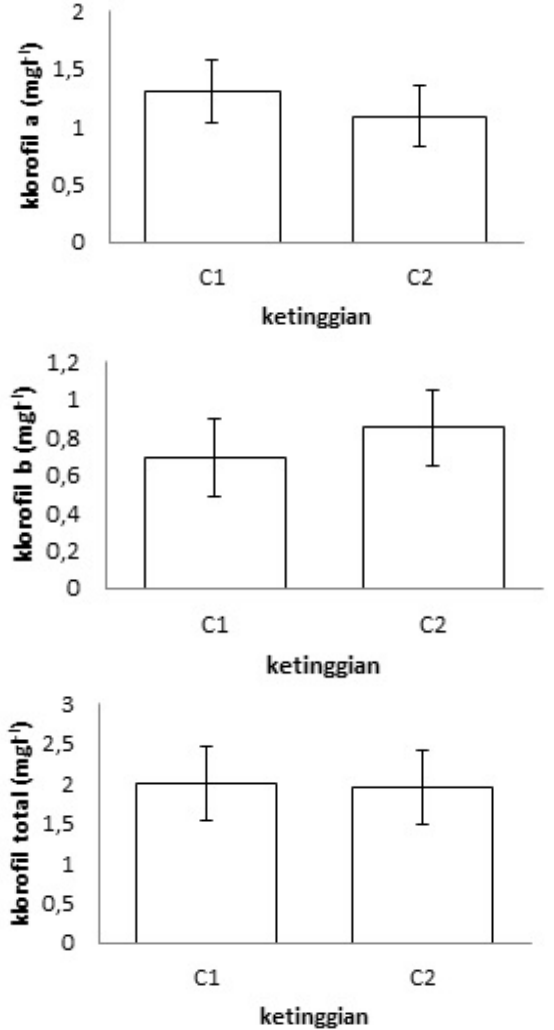

Gambar 3. Kandungan klorofil lumut spesies C pada tiap ketinggian
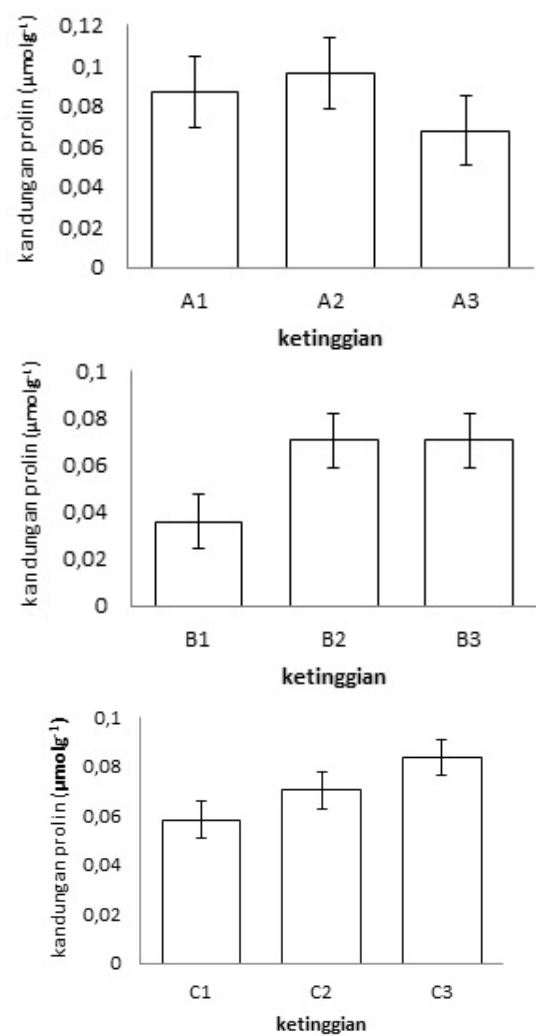

Gambar 4. Kandungan prolin lumut pada beberapa spesies pada berbagai ketinggian.

\section{PEMBAHASAN}

Kandungan klorofilcenderung meningkatpada ketinggian yang lebih rendah (intensitas cahaya makin besar). Hal ini sesuai dengan penelitian 
yang menyatakan lumut yang mendapatkan sinar matahari yang lebih banyak kandungan klorofilnya lebih tinggi dari pada lumut yang berada pada tempat teduh/ shady(Marchall, 2004). Namun, pada penelitian ini, dimana akses asap dari Kawah Domas terbesar pada titik ketinggian kedua, maka kandungan klorofil lumut di titik ini menunjukkan angka paling rendah diantara kedua titik ketinggian lainnya, yaitu sebesar 1,06 $\mathrm{mgl}^{-1}$. Hal ini mungkin sekali disebabkan oleh asap belerang yang berasal dari Kawah Domas, yang terletak tepat di bawah lokasi titik ketinggia kedua. Dalam penelitian lain disebutkan bahwa paparan gas sulfur dioksida pada lumut dapat menyebabkan penurunan fotosintesis karena rusaknya pigmen fotosintesis akibat pengaruh sulfur dioksida tersebut. Ketiadaan lapisan kutikula pada lumut menyebabkan lumut menjadi sangat sensitif terhadap polutan, termasuk sulfur (WHO, 2000).

Secara umum, kadar prolin relatif tinggi pada ketinggian II(1.721 m dpl), hal ini disebabkan oleh lokasi habitat lumut tersebut tepat berada di atas mulut Kawah Domas yang memiliki akses langsung terhadap asap dari Kawah Domas. Jadi bisa di asumsikan bahwa kondisi fisiologis lumut yang berada pada lokasi II lebih stres dibanding lokasi yang lainnya. Selain itu, sebenarnya ada faktor lain yang mempengaruhi kandungan prolin, yaitu cekaman kekeringan. Hal ini berkaitan dengan peran prolin sebagai osmoprotein, sehingga produksi prolin yang berlebihan dapat meningkatkan ketahanan tanaman terhadap cekaman kekeringan.

Fluktuasi dalam konsentrasi prolin merefleksikan dinamika dan perubahan kondisi lingkungan di sekitar Kawah Ratu sampai Kawah Domas. Kemungkinan kondisi dari kelembaban tanah, salinitas tanah, dan sinar matahari yang menciptakan kondisi menjadi lebih kering (Taufikurrahman, 1993).

\section{KESIMPULAN}

Karakteristik fisiologis lumut bervariasi pada tiap ketinggian. Kandungan klorofil pada lumut berbeda pada tiap ketinggian, yaitu semakin rendah pada ketinggian yang makin tinggi. Kandungan prolin tidak berbeda secara siginifikan pada tiap ketinggian, serta cenderung lebih dipengaruhi oleh kondisi udara yang berkorelasi dengan jarak habitat lumut dengan Kawah Domas, yang diduga dapat menyebabkan terjadinya cekaman fisiologis pada lumut.

\section{DAFTAR PUSTAKA}

Dharmawan A. 2005. Ekologi Hewan. Malang: UM Press.

Daryat. 2008. Pengaruh Faktor Fisiografis Terhadap Produksi Damar Mata Kucing (Shorea Javanica K Et. V) Di Pekon Pahmunga nKecamatan Pesisir Tengah Kabupaten Lampung Barat. Seminar Hasil Penelitian \& Pengabdian kepada Masyarakat, Unila.

Siregar H. 2010. Keanekaragaman Lumut di Kawasa Hutan Lindung Aek Nauli, Sumatera Utara. Skripsi Sarjana. Program studi Biologi. Universitas Sumatera Utara, Medan. Indonesia.

Hasan M, Ariyanti N. S. 2004.Mengenal Bryophyta (Lumut) Taman Nasional. Gunung Gede Pangrango Volume 1. Balai Taman Nasional Gunung Gede Pangrango, Cibodas.

Iskandar E. A. P, Nasution T, Suharja. 2008. Eksplorasi Bryophyta di Kawasan Cagar Alam Gunung Tangkuban Perahu. Laporan Eksplorasi. UPT Balai Konservasi Tumbuhan. Lembaga Ilmu Penelitian Indonesia. Bogor. Indonesia.

Indrawan M, Primack RB, Supriatna J. 2007. Biologi Konservasi. Jakarta: Yayasan Obor Indonesia.

Lakitan B. 1995. Dasar-Dasar Fisiologi Tumbuhan. Jakarta: Rajawali Press.

Marschall, M. And Michael C. F. P. 2004. Are Bryophytes Shade Plants? Photosynthetic Light Responses and Proportions of Chlorophyll a, Chlorophyll $\mathrm{b}$ and Total Carotenoids. Annals of Botany 94: 593-603, 2004

Pitriana P. 2003. Perbedaan Kondisi Ekofisiologis Lumut Kerak Parmelia sp. di Hutan Campuran, Hutan Pinus dan Hutan Transisi Gunung Tangkuban Perahu: Kaitan dengan Iklim Mikro dan Substrat Tumbuh. Skripsi Sarjana. Departemen Biologi. Institut Teknologi Bandung. Indonesia.

Raffensperger J.C, Wood C.L. 2005. Success of Epiphytic Bryophytes Over an Elevational Gradient. Monteverde : Dartmouth Studies in Tropical Ecology.

Taufikurrahman. 1993. The responses of saltmarsh and inland clones of Trifoliumrepensto salinity: ecophysiological studies. PhD Thesis. University College of Swansea.

White, T. A., Navasona K., Donald F. B., and John J. T. 2007. Structure and Kinetics of Monofunctional Proline Dehydrogenase from Thermus thermophilus. The Journal of Biological Chemistry Vol. 282, No. 19, pp. 14316-14327. [WHO]. 2000. Guidelines Air Quality. Denmark.

Yuliani, D. 2010.Kajian Aktivitas Antioksi dan Fraksi Etanol Jintan Hitam (Nigella sativa L.). Skripsi Tidak Diterbitkan. Malang: Jurusan Kimia Fakultas Sains dan Tekonologi Universitas Islam Negeri Maliki Malang. 